\title{
Dynamic capabilities triggered by cloud sourcing: a stage-based model of business model innovation
}

\author{
Mirella Muhic $^{1} \cdot$ Lars Bengtsson $^{1}$ iD
}

Received: 1 February 2019 / Accepted: 13 November 2019 / Published online: 28 November 2019

(c) The Author(s) 2019

\begin{abstract}
Current research offers very limited insights on the process of how the adoption and continued use of cloud sourcing might trigger and push the development of business model innovation and affect the competitive advantage of a firm. Applying an abductive approach, with two longitudinal case studies of cloud sourcing firms, and a theoretical framework based on stage-based models of business model innovation and the dynamic capability view of the firm, we develop a model of stage-based business model innovation related to the adoption and continued use of cloud sourcing. The model identifies three business model innovation stages characterized by specific types of capabilities. In between the three stages, we identify three dynamic junctures that the firm and its managers have to overcome to progress from one stage to another. In the dynamic junctures three types of dynamic capabilities were key; sensing, seizing and transformation capabilities, to pass to the next stage. The model contributes to a better understanding of the evolution of dynamic capabilities as well as the evolution of the cloud sourcing firm and cloud-based business model innovation.
\end{abstract}

Keywords Cloud sourcing · Stage based model $\cdot$ Dynamic capabilities · Business model innovation

JEL Classification M15 - O32

\section{Introduction}

The introduction of cloud computing (Schneider and Sunyaev 2016) and cloud sourcing (Muhic and Johansson 2014; Willcocks et al. 2013a, b) represent a potentially important option to not only simplify the outsourcing of IT elements but more

Lars Bengtsson

lars.bengtsson@design.lth.se

1 Division of Innovation Engineering, Department of Design Sciences, Faculty of Engineering LTH, Lund University, PO Box 118, 22100 Lund, Sweden 
importantly to develop strategic innovation capabilities in order to strengthen the firm's competitive advantage (Legner et al. 2017; Willcocks et al. 2013b). However, given the historic technology focus of the IT-function, the traditional role as an internal service provider and the separation between the IT-department and business departments (Legner et al. 2017; Vithayathil 2018) the potential of cloud sourcing to become a driver of strategic innovation remains problematic and challenging (Vithayathil 2018).

Cloud computing provides on-demand access to a pool of scalable and manageable IT-resources on a pay-per-use basis (Mell and Grance 2011). IT-resources here refer to infrastructure and hardware (Infrastructure as a Service, IaaS), platforms for development (Platforms as a Service, PaaS), and application software (Software as a Service, SaaS) (Mell and Grance 2011). Examples of IaaS are Amazon EC2 who offers virtualized computing services (servers, network, data storage) where customers can deploy, control and run any software, operating systems as well as applications, without owning, managing or operating the virtualized IT-resources. PaaS, e.g., Microsoft Azure, offers an integrated environment where customers and their IT-consultants can design, build, test and deploy custom applications. SaaS offers software applications that are run on cloud infrastructure, remotely accessed through the internet by the customer firm's clients, typically through a web browser. Examples include many standard applications such as e-mail and office applications, to complex applications such as enterprise resource planning (ERP) systems such as SAP Business by Design. The key characteristics of cloud computing has been described by Mell and Grance (2011) as: the provision of (1) on-demand self-service access to (2) virtualized, shared, and managed IT resources, (3) scalable ondemand, (4) available over a network, and (5) priced on a pay-per-use basis.

The decision to outsource a firm's IT-resources and activities to the cloud, i.e., to adopt, integrate and continued use of cloud services from external cloud providers, we here define as cloud sourcing (Muhic and Johansson 2014; Schneider and Sunyaev 2016). Current research on cloud sourcing from an organizational perspective has been dominated by issues regarding the characteristics and advantages of cloud sourcing (e.g., Mell and Grance 2011), cloud adoption (e.g., Schneider and Sunyaev 2016) and to a lesser degree on cloud continuance (e.g., Ratten 2016). The research shows that changing to cloud sourcing, from traditional IT-outsourcing, is a challenging proposition, especially for larger firms (Willcocks et al. 2013a, b). The advantages of cloud sourcing, such as relief of managing IT-resources, on-demand, and pay-per-use, do not seem so easy to reap (Willcocks et al. 2013a). For continued use of cloud sourcing current research indicate that factors such as personal attitudes, behavior characteristics and leadership support (Ratten 2016) are important. However, current research on cloud adoption and continuance is primarily technical (Schneider and Sunyaev 2016), or end-user oriented (Ratten 2016) and to a large degree based on larger data-sets and cross-sectional. Thus, current research offers very limited insights on the process of how the adoption and continued use of cloud sourcing might trigger and push the development of business model innovation and affect the competitive advantage of a firm. Specifically, many firms with traditional IT-functions lack capabilities to describe and analyze their function concerning business model 
innovation and the firm's sources of competitive advantages (Willcocks et al. $2013 \mathrm{a}, \mathrm{b})$ and how they might develop over time. Secondly, most firms with traditional IT-function and traditional outsourcing lack the capability to innovate business models (Willcocks et al. 2013a, b). Thirdly, traditional IT-sourcing typically means a 1:1 relationship between the client and vendor (Vithayathil 2018), while cloud sourcing involves an arrangement of several cloud provider firms (cloud broker, cloud provider, cloud sub provider, IT-consultant firms), requiring a capability from the cloud sourcing firm to interact with and manage an eco-system of cloud provider firms (Willcocks et al. 2013a, b).

The lack of dynamic capabilities might hinder cloud sourcing firms from utilizing the full potential of cloud computing and other related new technologies, e.g., internet of things, artificial intelligence, as well as the opportunities to transform the firm's business model and strengthen competitive advantage (cf. Bouncken et al. 2019; Teece 2007, 2018). However, if the cloud sourcing firm can sense and seize the opportunities related to cloud computing, it might be able to realign its structures, cultures and business models to gain competitive advantage (cf. Bouncken et al. 2019; Teece 2007, 2018).

This paper aims to address these issues by an abductive approach, a combination of an empirical investigation of two case studies of firms and their processes of implementing cloud sourcing over time and a theoretical framework of stages of business model innovation and the dynamic capabilities theory of the firm. We specifically address two research questions:

1. What stages do cloud sourcing firms go through in their business model innovation process?

2. What are the key challenges cloud sourcing firms face in their business model innovation process?

We drew upon two separate works of research literature theoretically guiding our abductive approach. First, we draw on research relating to stage-based models of business model innovation. Overall, stage-based models describe organizational characteristics in each development stage and changes required in practices to progress to the next stage (Greiner 1972; Miller and Friesen 1984; Romanelli and Tushman 1994; Smith 1985). The role of feedback and non-linear development have been increasingly recognized in later stage model research (Eisenhardt 1989; Helfat and Peteraf 2003). Accommodating these aspects we aim to understand how, when and why the transitions occur in the strategic innovation trajectory of cloud sourcing. Second, we will use the dynamic capability view of the firm (Bharadwaj et al. 2013; Teece 2007, 2018), that views the firm as a heterogeneous bundle of dynamic capabilities, related semi-permanently to the management of the firm. Deficiencies and weaknesses in firm dynamic capabilities might constrain the firm's use of cloud sourcing and business model innovation (Helfat and Peteraf 2003; Legner et al. 2017). A non-business oriented environment such as a traditional IT-function combined with a traditional IT outsourcing solution may further exacerbate the development constraints. A dynamic capability 
view suggests that to progress through stages of business model innovation, cloud sourcing firms have to develop and deploy relevant dynamic capabilities (Teece 2007, 2018).

The following section of the paper presents the theoretical framework and the third section of the abductive approach and methods of data collection and analysis. The fourth section presents the empirical context, the two cloud sourcing firms. The fifth section summarizes the findings and in the sixth section a discussion and theoretical integration results in a stage-model of business model innovation of the cloud sourcing firm. The final section discusses the theoretical contributions, limitations of the study and implications for the management of the cloud sourcing firm.

\section{Theoretical framework}

\subsection{Dynamic capabilities and business model innovation}

The dynamic capability theory of the firm (Teece 2007, 2018) is an extension and development of the resource-based theory of the firm (Barney 1991; Wernerfelt 1984). Both theories assume that valuable, rare and hard-to-imitate or substitute resources and capabilities are the basis of a firm's competitive advantage. The difference is that the resource-based theory of the firm maintains the view that these strategic resources could lead to sustained competitive advantage while the dynamic capability theory assumes that the value of strategic resources will erode over time as competition will catch-up (Teece 2018). The only competitive advantage that will last over time is the ability to develop, re-configure and divest the firm's capabilities in a more effective way than its competitors (Teece 2007). Dynamic capabilities include the sensing, seizing and transforming capabilities that are needed to design, implement and innovate the business model (Teece 2018). The dynamic capabilities depend on managerial competencies to identify opportunities, commit resources to the development and refinement of parts of the business model, and make structural and cultural alignments resulting in a transformation of the firm and its business model (Teece 2018).

The role of strategy concerning dynamic capabilities has been debated but we here adhere to the view of Teece (2018), that strategy is about how the firm will compete. A common trigger for sensing a business opportunity are technological possibilities, i.e., the development of new technology. A new technology, like cloud computing, enabling sourcing IT-systems in a new way, cloud sourcing, may set off a transformation process driven by the firm's dynamic capabilities. Cloud computing and cloud sourcing represent new forms of organizational flexibility that could be used to innovate the firm's business model (Teece 2018). The presence and strength of dynamic capabilities decide the speed and degree of renewal and reconfiguration of resources and ordinary capabilities in response to market changes. Vice versa, less-developed and weak dynamic capabilities, will hinder the transformation process.

Business model innovation can be understood in different ways (Bouncken et al. 2019; Foss and Saebi 2017, 2018; Spieth et al. 2014). Based one of the most utilized 
definitions of a business model “...the design or architecture of the value creation, delivery, and capture mechanisms" (Teece 2010:172) employed in the research literature, we here adhere to the definition of business model innovation proposed by Foss and Saebi (2017:201): “designed, novel, and non-trivial changes to key elements of a firm's business model and/or the architecture linking these elements". With this definition, we can differentiate between innovations in key elements and more architectural or configurational innovations as employed by Clauß et al. (2019) in their study of business model innovation among SMEs in the electronics industry. Examples of innovations in key elements related to cloud sourcing could be the introduction of new service based on software (SaaS) or the introduction of a new internal process also based on SaaS or new platforms (PaaS). Examples of architectural innovations related to cloud sourcing could be changing from a bundled and integrated service offer delivered entirely by the supplier firm to an unbundled and modular service offer delivered partly or wholly by third-party firms.

While the role of technical innovation, such as cloud computing, is well recognized as a trigger for transformation of business models (e.g. Kraus et al. 2019; Teece et al. 2016), the process following the trigger is not very well understood in the dynamic capabilities theory and there is no coherent view of the transformation process within firms (Salvato and Vassolo 2018) or across partner firms (Bouncken and Kraus 2013; Bouncken et al. 2016). That is why we now turn to the stage-based models.

\subsection{Stage-based models}

Stage-based models of business development and innovation have a long history in management research with important research contributions based on case studies starting at the beginning of 1970s (e.g. Greiner 1972; Normann 1971). Later, large empirical studies confirmed and deepened our understanding of stage-based firm development (e.g., Miller and Friesen 1984; Romanelli and Tushman 1994) as a process largely driven by technological development (Tushman and Anderson 1986) resulting in relatively long periods of stability in firm development followed by relatively short periods of fundamental changes, the so-called punctuated equilibrium model of organizational transformation (Romanelli and Tushman 1994). Overall, stage-based models describe organizational characteristics in each development stage and changes required in practices to progress to the next stage (Greiner 1972; Miller and Friesen 1984; Smith 1985).

The researchers developing the dynamic capability theory often stress the need for firms and their management to continuously and vigorously change and innovate (e.g. Eisenhardt and Martin 2000; Teece 2007, 2018), however at the same time organizational structures and cultures are path dependent, inert and resistant to change (Hannan and Freeman 1984). While simultaneous exploration and exploitation are preferable for a firm facing a dynamic environment (March 1991), empirical research has shown that exploration and exploitation activities tend to drive out each other making it difficult for firms to perform both activities at the same time (Holmqvist 2009). Instead, we will here infer a temporal division of exploration and 
exploitation activities as the stage-based models imply. That firms manage dynamic environments, with success, by temporally dividing exploration and exploitation activities, have been confirmed in many empirical studies as related above.

\section{Research design: the abductive approach}

We utilize an abductive approach (Dubois and Gadde 2002) combining two case studies on the overall management in two firms which have adopted cloud sourcing and a theoretical framework combining stage-based models of firm development with a dynamic capability view of the firm. In line with Gummesson (2005) and Creswell (2013), data collection and data analysis were conducted in parallel and several rounds of data collection and subsequent data analysis. In other words, data collection, data analysis, and writing process were interrelated and constantly shifting between the empirical world and the theoretical framework (Dubois and Gadde 2002). The data was analyzed by systematically grouping and combining the insights into themes (Creswell 2013; Miles and Huberman 1994), which were subsequently constantly matched with the theoretical framework to direct the research in the direction of abductive iteration (Dubois and Gadde 2002).

\subsection{Data collection, case description, and analysis}

The research process started with two case studies of firms that had implemented cloud sourcing covering 2 years. We choose to study one cloud sourcing firm (CSA) that had mainly positive experiences from implementing cloud sourcing and another firm (CS-B) that had mainly troublesome and problematic experiences with the same process. The initial research aim was to understand the differences between the two implementation processes, i.e., how and why they evolved into a more positive or negative development path. We made three key findings in our initial case studies. First, both of the implementation processes started as technology-triggered processes trying to make the cloud sourcing solution work as intended. Second, in both processes, more business-oriented issues started to appear after the cloud sourcing solution had stabilized from a technical and operational perspective. Third, the main difference between the two implementation processes seemed to be that in CS-A the firm sensed and seized many more business opportunities with cloud sourcing than CS-B. CS-A also involved themselves in more development work and re-organization activities related to cloud sourcing than CS-B.

The initial case study findings led to the conclusion that business model innovation in the firm related to the cloud sourcing implementation occurred in stages where certain capabilities (or lack thereof) in the firms made it possible to advance to a new development stage. As we were aware of stage development models and the dynamic capabilities view of the firm we decided to use and integrate these theories to further develop our findings. The stage-based models sensitized us to view the process of development as a series of stages where the firm's practices related to cloud sourcing became more advanced over time, i.e., 
advancing from providing IT-services with the assistance of cloud sourcing, to becoming more integrated in the firm's strategic development and a source for business model innovation. The dynamic capability-based model made us sensitive to possible critical dynamic junctures between the stages, where sensing, seizing and transforming activities played major roles to pass into a new stage of development or possibly hinder further development due to lack of sensing, seizing and transforming capabilities. Based on the theories we re-analyzed the case studies as well as complemented the case studies with additional interviews. This resulted in a more elaborate description of development stages and critical dynamic junctures where available or lack of available dynamic capabilities made it either possible or hard to progress to the next development stage.

The two cases, cloud customers CS-A and CS-B, include related cloud vendor firms; i.e., cloud providers, sub providers, and cloud brokers to comprehensively study the evolving cloud sourcing process. There were eight partners involved in each of the two studied cases, 16 companies in total. The data was collected primarily through semi-structured interviews (66 formal interviews in total), onsite observations in the form of meeting participations (30 formal and 20 informal weekly meetings), and documents such as SLA, internal reports, meeting notes and protocols, presentations, and change-orders (130 documents in total). Interviews were conducted with managers, individual users, developers, project leaders, and employees from different departments using cloud systems at CS-A and CS-B, as well as managers and project employees from their cloud providing partners. In addition, we attended 50 meetings between our case companies and their 16 respective cloud providing partners. Our data collection started with interviewing the top IT management at the case companies and continuing with heads of departments and employees down to the cloud sourcing providers. The participation of both case firms' top management ensured the firms' willingness to cooperate, availability of multiple sources, and the potential for purposeful sampling (Peppard 2001; Yin 1989). Moreover, a researcher in our team obtained a workspace at the headquarters of both case companies and spent 2 months at CS-A and 1 month at CS-B. This enabled the researcher to participate in the everyday activities on site as well as key insights into strategic intents and practices, which helped in checking the validity of early results, as well as furthering credibility and authenticity of our findings (Miles and Huberman 1994). Also, discussions with various employees during this three-month fieldwork enriched the contextual understanding of the cases. In conclusion, this approach enabled us to analyze practices from the perspectives of professionals and helped to engage in productive discussions with employees daily (Geertz 1988; Ngwenyama and Klein 1994).

In this study, we define the cloud sourcing process as the unit of analysis, with the rest of the firm and its managers as well as external cloud providers as the relevant surrounding environment. We particularly focus on mid-size firms with prior use of traditional IT-outsourcing and an IT-function with the traditional role as an internal service provider which has decided to utilize cloud sourcing. 


\section{Empirical context: two case studies of implementing cloud sourcing}

The first case company in our study was CS-A, a global leader in industrial maintenance, with 30 years of experience in industrial maintenance management and execution. The company operates across six continents, on 400 sites in 28 countries with 3000 employees in total, commonly working in 24/7 virtual teams. CS-A entire systems are fully cloud sourced, utilizing all forms of the cloud IaaS, PaaS and SaaS, with cloud providers located in India, Belgium, UK, Finland, Spain, and the Netherlands. For example, Customer Relationship Management (CRM), Enterprise Resource Planning (ERP), employee's documents, and other systems are located in the cloud. CS-A is a successful case of cloud sourcing as it has implemented of full cloud sourcing in less than 2 years.

Our second case company is CS-B, a Northern European waste management company with some 300 employees. The company is owned by 14 municipalities with a joint population of slightly more than 710,000 and is commissioned to manage the household waste in all owner municipalities as well as for approximately 6000 corporate customers. The company utilizes all forms of cloud sourcing; IaaS, PaaS and SaaS, and has transferred seven systems to the cloud, i.e., they have retained some systems in-house. They have been in the cloud sourcing process for roughly 5 years. Their cloud providers are located in Sweden, Austria, and the USA. CS-B has had several problems when implementing cloud sourcing and the process has been far from straightforward.

In terms of key element business model innovations, i.e., new (to the firm) and architectural innovations, related to cloud sourcing, the two cases show very different profiles. In CS-A we see evidence of both key element and architectural innovations, while CS-B has innovated mostly new in key elements in internal processes and organizational innovations to handle cloud sourcing. Some examples of key elements and architectural business model innovations are listed below in Table 1.

\section{Findings}

The analysis of the cases, using the theoretical framework, suggests three key findings. First, the development is non-linear over three distinct stages. While both firms went through the first stage into the second stage, CS-A progressed further to the third stage. CS-B progressed to the second stage but has later oscillated between the first and second stage. Second, the cloud sourcing firms encountered dynamic junctures when progressing from one stage to another. These dynamic junctures had to be overcome to make the transition from one stage to the next. In each dynamic juncture, the management of the firms had to draw on the three types of dynamic capabilities: sensing, seizing and transforming capabilities, to progress to the next stage. Third, the firm differed before and 


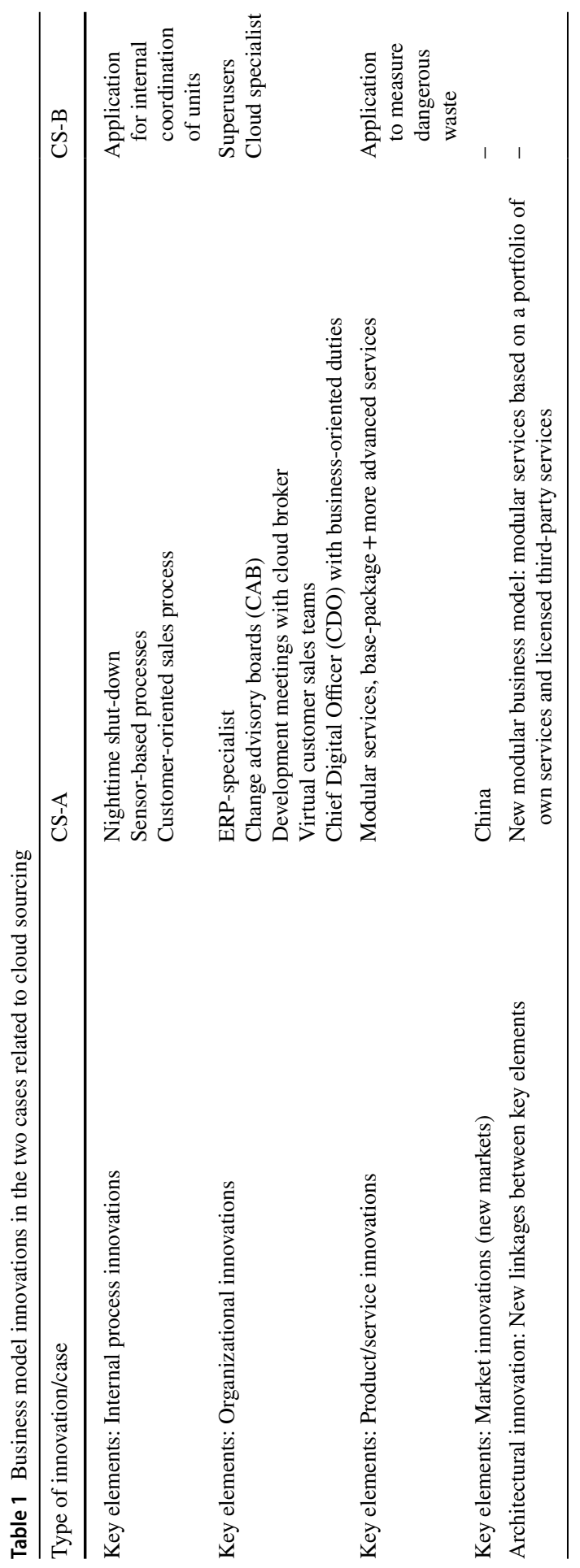


after each stage in qualitative terms, i.e., capabilities and relations were different, even though the differences were much large in CS-A:s than in CS-B. Thus, dynamic junctures are characterized by significant changes in firm capabilities and relations with cloud sourcing partners. We recognize that cloud sourcing firms do not have to go through discrete stages of development, but rather through non-linear stages divided by the dynamic junctures. We will examine these findings in an integrated fashion describing the stages and dynamic junctures as they appear in our integrated stage-based model of the cloud sourcing firm.

\subsection{The decision to cloud source}

Both firms decided to cloud source due to the usual arguments for cloud sourcing relative to traditional outsourcing: lower cost, facilitating expansion, standardization of processes and more frequent maintenance of programs and systems. In case of CS-A, the decision coincided with spinning out the firm from a major corporation, while in CS-B there were no major organizational changes in conjunction with the decision to cloud source. The management in both firms did not mention any major strategic or business model changes as motives for the decision to cloud source. The overall motives concerned greater flexibility and cost.

\subsection{Dynamic juncture one: key elements business model innovation-new internal processes and new ways to organize}

When starting to implement cloud sourcing, transferring systems incrementally to the cloud, both firms encountered several issues that they had not experienced before. One issue was the frequent, typically every week, updates of programs and systems that made users of the systems confused. The users were used to updates of systems once every year or so. Now, the updates and changes were more frequent and at the beginning not announced from the cloud system provider. The users could suddenly meet a new interface for the same system from one day to another. A new routine had to be established concerning scheduling and informing about the content of the updates. The cloud provider firm proposed that skillful users at the CS-B should be appointed "super-users" and get special training and tasks to assist their peers with different kinds of problems related to updates and general questions. CS-B also did so and this worked well.

One of the systems much used in both firms is the ERP-system (Enterprise Resource Planning). Frequent updates and the complexity of the system resulted in many problems and questions to the cloud provider. To structure this process and solve some of the problems already in the customer firm an ERP-specialist was appointed and trained to be the internal recipient of all questions and problems in CS-A. In case this person could not solve the problem, the ERP-specialist contacted a special contact person at the cloud provider firm to try to solve the problem.

Chief IT Officer (CIO) of CS-A was overall positive to the frequent updates of the cloud systems referring to higher security of the systems, constant development and improvement which in turn pushes the internal organisation to change its work 
routines accordingly - and thereby become a constantly evolving organisation in a higher pace than with traditional IT outsourcing. This implies refined work processes and value-added from the cloud sourcing in the form of internal process innovation. The more efficient way of working releases time for CS-A to focus on its core business. Cloud sourcing also enables easier collaboration between employees across the globe, by encouraging collaborative functions integrated with the cloud systems - e.g. by reducing the amount of emails sent through real-time collaboration through the cloud platform.

The level of IT-competence was generally a bit lower at CS-B than CS-A. Both the cloud vendors and the management of CS-B experienced problems in communicating due to the level of technical competence. CS-B then hired a "cloud-specialist", a person with prior experience of cloud sourcing in another firm, resulting in somewhat better communication. CS-A and their cloud providers organized a new weekly meeting, called Change Advisory Board (CAB), to handle all kind of operational and technical problems and issues related to cloud sourcing. CABs took place on Skype and worked well. CS-A also organized a monthly meeting, so-called ITOs, to discuss more development-oriented issues, with the cloud broker firm. The ITOs were organized as ad-hoc meetings, roughly one time every fortnight, when needed. CS-B has not organized any permanent organizational structures to handle coordination and development issues.

When most of the immediate technical and operational implementation problems were under control both firms launched other small development projects to utilize the flexibility of cloud sourcing. In CS-A an external consultant was commissioned to investigate shutting down systems in the night-time, as many of these systems were idle during the night, and proposed a solution that resulted in substantial cost savings for CS-A. CS-B developed an app that could be used by all waste-collecting units and better coordinate their routes and to able to re-direct the units in real-time.

\subsection{Stage 1: key elements business model innovation-Internal processes and organizational innovations}

After some time most implementation problems were routinely handled through the introduction of new routines/processes and minor changes in organizational structures, such as appointing specialists and a new type of meeting structures. From a technical and operational point of view, the systems worked and the staff competently operated the systems. Moreover, the Chief IT officer (CIO) of both firms, the specialists in collaboration with cloud providers and commissioned external consultants were identifying internal process improvements and changes that could utilize some of the flexibility advantages of cloud sourcing.

CS-B experienced after some time problems with one of its cloud providing firms that could not deliver according to the agreed service-level agreement. Thus, it had terminated the contract and find a new cloud provider. This led to new implementation problems and CS-B re-experienced some of the problems they had encountered in dynamic juncture one. 


\subsection{Dynamic juncture two: key elements business model innovation-new products and markets}

One of the advantages of cloud sourcing is that it facilitates expansion, both in terms of adding new geographic markets and new services. This is especially evident when the services can be developed on the cloud platform (PaaS) or delivered as a software-based service (SaaS). CS-A's services consist of both physical processes and physical presence, but most of their processes for maintaining industrial machines and equipment are based on software systems that monitor and control the customer firm's industrial machines. CS-A had plans to expand to new markets, primarily China but also other Asian markets with industrial manufacturers. To increase the pace and capacity to expand in Asia, CS-A introduced a new unit headed by a new Vice-president for Sales in Asia. To facilitate expansion to China a new sales process, based on virtual sales teams and customerorientation, i.e., starting with customer needs and customer expectations, was developed. Discussion of adding new digital services, aiming for more advanced predictive maintenance, started.

At this juncture, the CIO at CS-A started to plan for the development of new databased products. The possibility to collect more data with sensors in addition to the data CS-A already collected attracted the CIO. The leadership of CS-A decided to hire a new Chief Digital Officer (CDO), who was given the task to develop a sensor-solution to collect more data from the machines that CS-A maintain and to develop new services based on the collected data. Overall, the new CDO was expected to be more involved in business-oriented development issues due to the hiring of the new CIO. CS-B has hired a cloud specialist, as described above, but in general the role has a more technical than business orientation. Thus, CS-B has limited capabilities to identify new services and propose the development of new services. However, there are a few examples of new services, based on a new software application. It is a software application that automatically scans waste for toxic and dangerous content. It is still in development and the main motivation for development is internal, i.e., safety, rather than business-oriented.

\subsection{Stage 2: key elements business model innovation-product and market innovations}

At this stage cloud sourcing and related technologies are viewed as triggers of product innovations and geographic expansion. By appointing new positions in technology- and product development, in marketing and sales, as well as regular meetings with cloud providers concerning development projects, routines and structures are at this stage in place to sense, seize and integrate candidates for geographic expansion and product/service innovations. The sensing, seizing and integration of new software-based services take place by interacting with cloud vendor firms, collaboration in developing new software-based services on the 
cloud platform and/or inviting partners in the cloud eco-system to deliver their software-based services through the cloud platform directly to the firm's customers product innovation At this stage IT-function and business development functions start to connect more routinely.

\subsection{Dynamic juncture three: architectural business model innovation-new linkages}

The modular structure of cloud sourcing, i.e., systems and data storage capacity could be added (or subtracted) from the cloud in modules with a corresponding cost structure, has at this point started to attract attention from the CIO and CDO together with other $\mathrm{C}$-level executives at $\mathrm{CS}-\mathrm{A}$ as a way to re-structure the value proposition for the customers when it comes to the digital part of the maintenance business and the whole maintenance business.

The value proposition to the customer is partly re-designed to a base package with certain digital tools and other organizational routines concerning safety and maintenance basics. Then the customer can add modules with more advanced digital tools based on added sensor-capabilities, online surveillance and big data analytics, to increase machine reliability and uptime further through predictive maintenance. The customer can also add service modules concerning operations of machines (and not only maintenance), some developed and delivered by CS-A, other services delivered by license from other cloud vendor firms.

To integrate the IT-function with the business development functions to deliver the base package and add-on modules to a potential customer a partly new sales process was created with virtual customer project teams and a customer-oriented sales process. The project team did a customer review of needs resulting in an agreement on a maintenance strategy and customer expectations. The customer project team normally recommended the customer to install and try the base package (or some variant of it) in 3 months to establish that maintenance basics were working. In the next 3 months, tangible results are demonstrated and root-causes to problems are analyzed resulting in recommendations for add-on modules for strengthening the predictive maintenance capabilities in the customer solution. In the following 3 months further tangible results are demonstrated, e.g., costs, uptime, and possible new digitals tools to install are discussed.

\subsection{Stage 3: architectural business model innovation}

At this stage cloud sourcing and related digital technologies are viewed as triggers and enablers of architectural and digital strategic innovation. The transformation of the organizational structure with a tighter communication between business- and IToriented C-level executives, routinized development meetings and interaction with cloud partner firms, together with virtual customer-oriented integrated sales teams and the modular structure of cloud sourcing and related digital technologies ensures that routines and structures in place to sense, seize and integrate candidates not only 
for key elements in the business model but also for new linkages between key elements, i.e., architectural business model innovations.

\subsection{Summarizing empirical case findings}

In Table 2 below we summarize the empirical case findings, together with exemplary interview quotes, according to dynamic capabilities (sense, seize and transforming), the capability stages and dynamic junctures.

\section{Discussion and theoretical integration}

We have here explored the transition phases experienced by firms implementing cloud sourcing. In particular, the study increases our understanding of the challenges faced by firms transitioning from traditional IT outsourcing to cloud sourcing. Conceptually we propose two major elements in the transition process (Fig. 1 below). First, the case study analysis shows that cloud sourcing firms go through several distinct stages of activity in their business model innovation process. The firms have to pass through the previous stage to progress to the next stage, though each stage is iterative and non-linear as firms may have to revise some earlier decisions and activities. Second, in between the stages, we found that the firms face dynamic junctures in terms of capabilities they needed to acquire or develop to progress to the next stage. To acquire or develop new capabilities the firms needed specific dynamic capabilities to overcome the dynamic juncture. If the specific dynamic capabilities were deficient the progression slowed down or stopped impeding further business model innovation.

Our theoretical framework combined with case empirical findings has resulted in a model describing the stages and junctures of business development related to the adoption and continuance use of cloud sourcing. The stage-based model indicates a linear development path, but as we have stressed, and as especially the CS-B case has shown, the development might go backward and oscillate between two stages. The important message from the model is that lack of or weak dynamic capabilities will make a transition to the next stage difficult or impossible. The presence of sensing capabilities is not enough, seizing and transformation capabilities also have to be available. The model is graphically shown in Fig. 1.

\section{Contributions and implications}

Our paper has modeled the business model innovation path of the cloud sourcing firm. We have identified three business model innovation stages characterized by specific types of capabilities. In between the three stages, we have identified three dynamic junctures that the firm and its managers have to overcome to progress from one stage to another. In the dynamic junctures three types of dynamic capabilities were key; sensing, seizing and transformation capabilities, to pass to the next stage. 


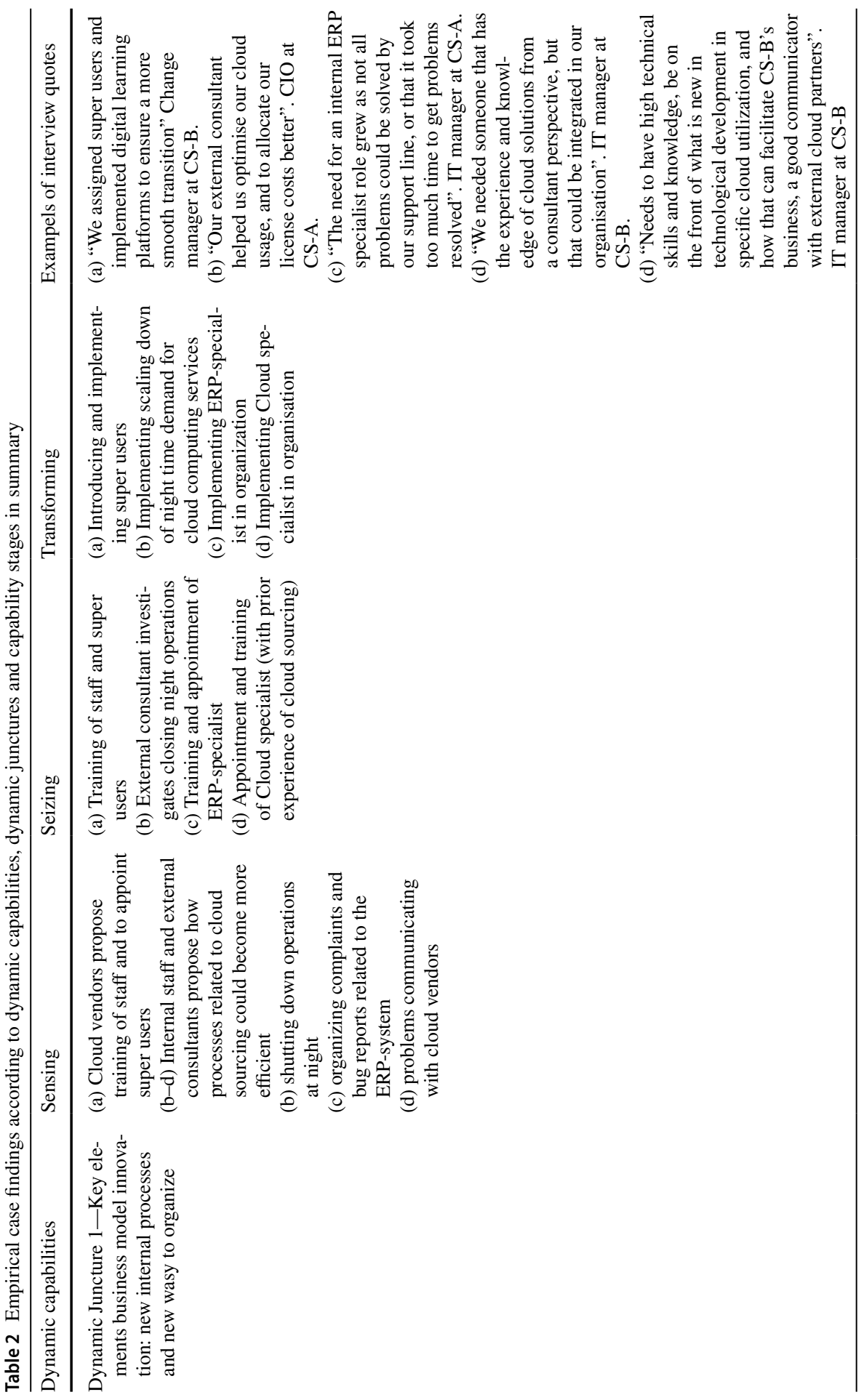




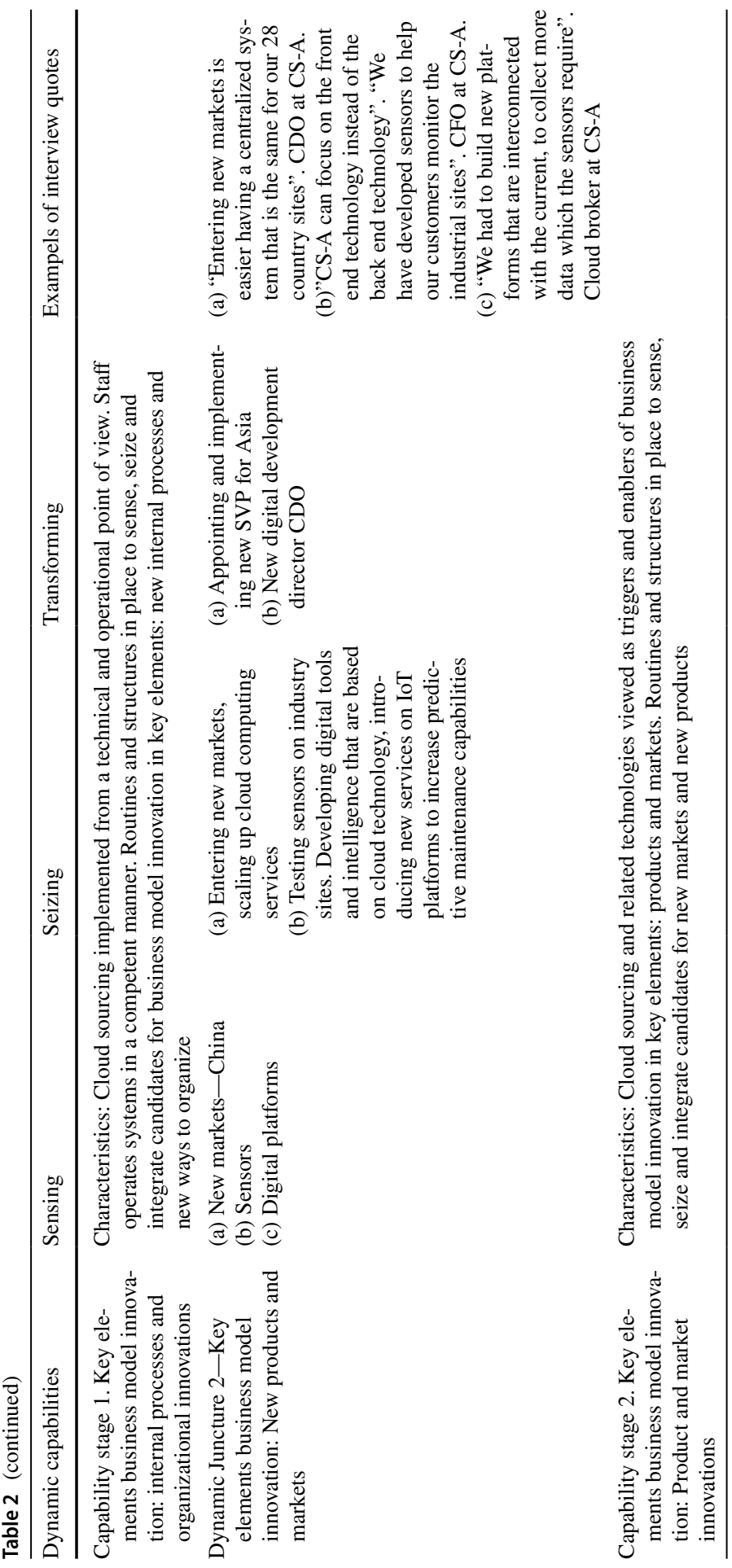




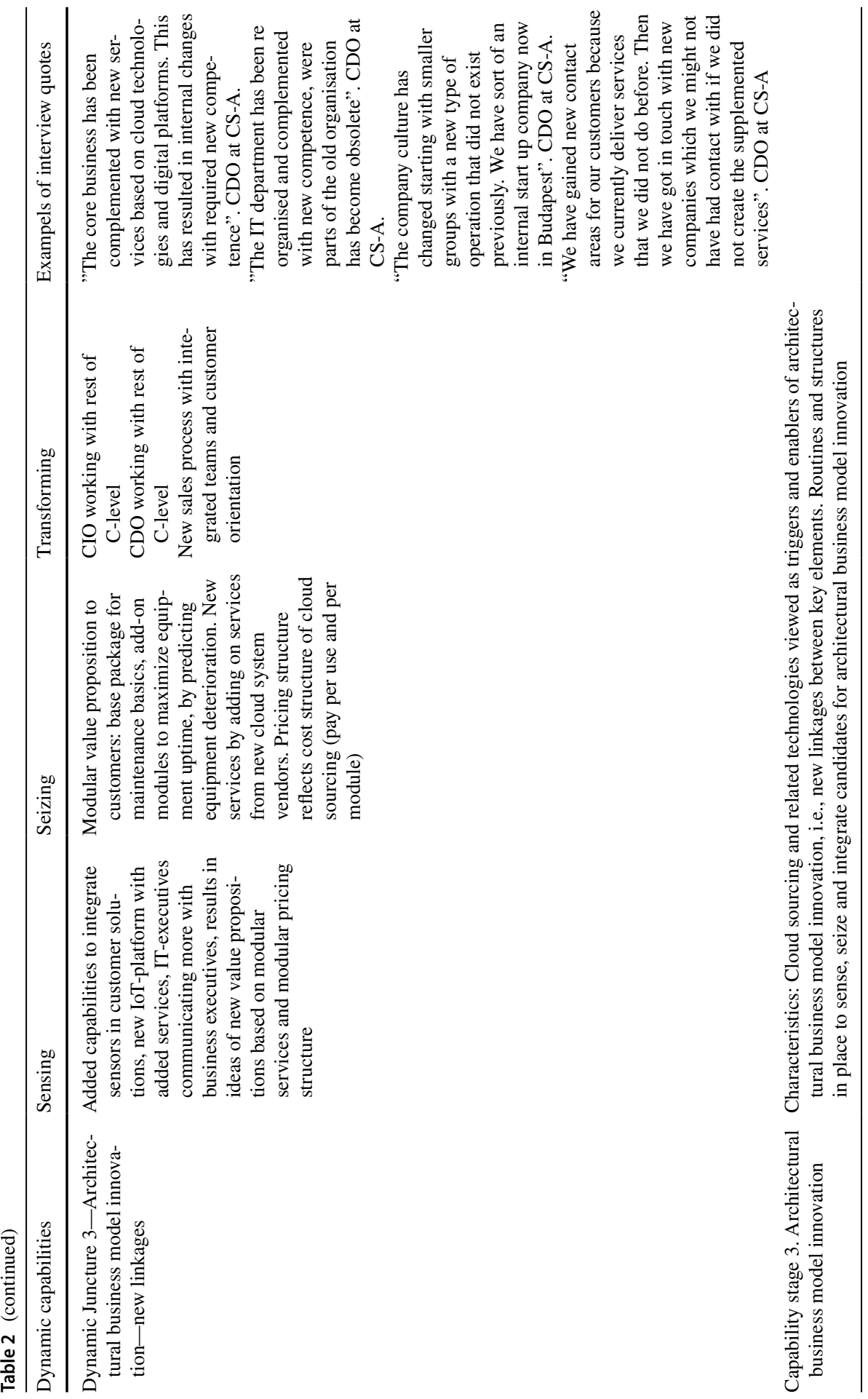




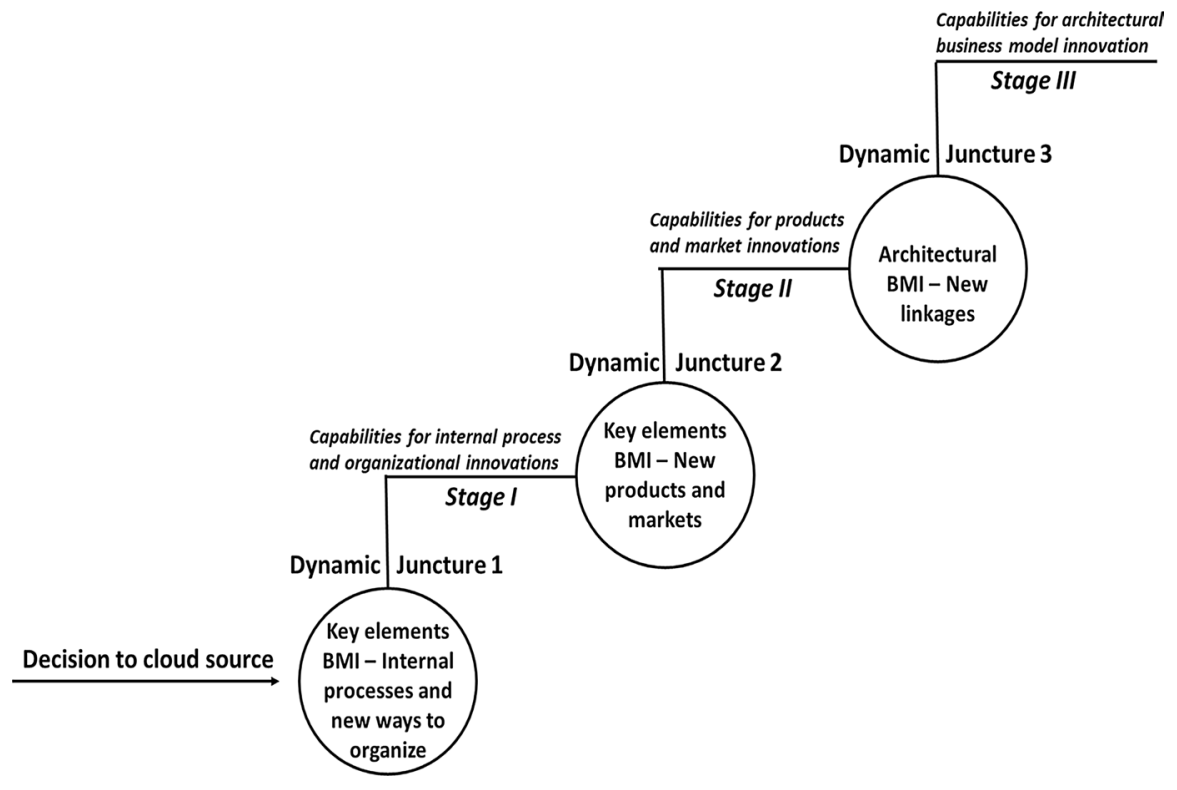

Fig. 1 Model of stage-based business model innovation (BMI) path related to cloud sourcing

We will now discuss the contributions and implications of our stage-based model of business model innovation related to cloud sourcing.

\subsection{Contributions}

We will here highlight four types of research contributions. First, much of the literature on cloud computing and cloud sourcing concerns cloud adoption and cloud continuance from a static perspective, i.e., based on cross-sectional data at one point in time (Schneider and Sunyaev 2016). Here we have taken a process view on cloud adoption and continuance stressing the capabilities to exploit cloud sourcing for business model innovation. The capabilities to change, the dynamic capabilities, are here key to reap the business model innovation advantages related to cloud sourcing.

Second, Willcocks et al. (2013a) concluded in their empirical investigation of cloud sourcing and innovation that progress in terms of cloud sourcing triggering innovation in firms seemed surprisingly slow and that technological challenges were among the most important challenges. Our model confirms that technology issues are challenging and indeed become a barrier for further business development in the initial stage. However, in later stages, according to our model and empirical findings, the lack of dynamic capabilities combining IT- and business competencies through re-aligning structures and internal culture, as well as establishing a good continuous innovation dialogue with the cloud providing partners, are more important challenges. 
Third, our research has treated the IT-function as part of the environment of the cloud sourcing process, thus we have not systematically studied the whole IT-function. However, it is clear from our study that the IT-function and its capabilities are key in the sensing, seizing and transforming of the business model related to cloud sourcing. Our model and empirical findings show that the IT-function must be able to lead and govern the collaboration with cloud providers, first organizing the routines for handling technical issues and internal key elements in the business model; i.e., internal process and organizational innovations. Then to organize and lead the cloud providers into a more business-oriented path with innovations in key elements in products/services and new markets. The most difficult and complex type of business model innovation; the architectural innovation, requring changes in linking of business model key elements, are based on dynamic capabilities integrating a business savvy ITfunction with a technically competent top management function that can orchestrate cloud source providers in a continuous business model innovation process. Overall our model agrees with the research done by Willcocks et al. (2013b) on the future of the IT-function that has adopted cloud sourcing.

Fourth, even though the dynamic capability view of the firm claims to explain the sources for competitiveness in dynamic environments (Teece 2007, 2018), it is a static theory, as we have limited understanding of the evolution of dynamic capabilities themselves (Helfat and Peteraf 2003). By combining the dynamic capability view of the firm (e.g. Teece 2007, 2018) with the stage-model (e.g., Romanelli and Tushman 1994) and lifecycle stages (Helfat and Peteraf 2003), we contribute to a better understanding of the evolution of dynamic capabilities. The stage-based model presented here, stress that not all the advantages of cloud sourcing can be exploited and explored at the same time, there is a temporal pattern to this process. Certainly, firms with more developed and strong dynamic capabilities relevant for cloud sourcing might be capable of executing a faster and more thorough process, but there would still be a temporal pattern according to our model.

\subsection{Limitations}

Our study does not come without limitations. First, our study is based on two cases of mid-sized firms implementing cloud sourcing. Further case studies, as well as larger-scale studies, are needed to confirm and develop our findings. Second, cloud computing technology, as well as cloud sourcing solutions, develop quite rapidly making our findings vulnerable to being out-dated. Thus, new studies are needed to study the evolvement over time of this phenomenon. Third, the cases are set in two particular industries: industrial maintenance, and waste management. Industries may differ, for instance in terms of requirements for strict safety and security regulations, as well as prior experience of IT and IT-outsourcing. Comparative studies, comparing cloud sourcing processes in different industries, would be preferable to identify different patterns in business model innovation related to cloud sourcing. 


\subsection{Implications for research and management of cloud sourcing and business model innovation}

The temporal pattern in our model implies that management of cloud sourcing should be carefully paced by managers that intend to cloud source or expand its current cloud sourcing further. First, managers need to be aware that even though many new ideas can be generated in relation to cloud sourcing, these ideas have to be combined with adequate development and transformation capabilities, to result in innovations. Second, business model innovations in internal key elements such as process innovations and organizational innovations might be the most important and feasible innovations in the initial phases of cloud sourcing to reap cost and efficiency advantages from cloud sourcing. Third, many innovations will come from collaboration with the cloud providing firms, thus inter-organizational innovation collaboration is key (cf. Bouncken et al. 2015). Fourth, for architectural business model innovation, the re-alignment and integration of IT-functions and business functions are imperative.

We propose further research to develop our stage model of cloud sourcing and business model innovation. The temporal pattern in our stage model is a testable proposition in large scale surveys concerning cloud sourcing in non-software intensive firms and the pattern of business model innovation. The context of cloud sourcing with its interorganizational relationships and collaborative innovation, sometimes with competing firms, might be a fruitful context for research on coopetition (Bouncken et al. 2015) as well as inter-organizational learning (Larsson et al. 1998).

Acknowledgements Open access funding provided by Lund University. The authors wish to thank guest editors and reviewers of the special issue "Knowledge- and Innovation-Based Business Models for Future Growth" in Review of Managerial Science and participants in our session at the INEKA Conference in Verona, Italy, 11-13 of June 2019, for constructive comments and sugegstions to improve the paper. Mirella Muhic acknowledges the financial support from the Swedish national research school in Management and IT.

Open Access This article is distributed under the terms of the Creative Commons Attribution 4.0 International License (http://creativecommons.org/licenses/by/4.0/), which permits unrestricted use, distribution, and reproduction in any medium, provided you give appropriate credit to the original author(s) and the source, provide a link to the Creative Commons license, and indicate if changes were made.

\section{References}

Barney J (1991) Firm resources and sustained competitive advantage. J Manag 17(1):99-120

Bharadwaj A, Sawy OE, Pavlou P, Venkatraman V (2013) Digital business strategy: toward a next generation of insights. MIS Q 37(2):471-482

Bouncken, RB, Roig-Tierno N, Kraus S (2019) Knowledge- and innovation-based business models for future growth: digitalized business models and portfolio considerations. In: Review of Managerial Science (in print), https://doi.org/10.1007/s11846-019-00366-z

Bouncken RB, Kraus S (2013) Innovation in knowledge-intensive industries: the double-edged sword of coopetition. J Bus Res 66(10):2060-2070

Bouncken RB, Gast J, Kraus S, Bogers M (2015) Coopetition: a systematic review, synthesis, and future research directions. RMS 9(3):577-601 
Bouncken RB, Plüschke BD, Pesch R, Kraus S (2016) Entrepreneurial orientation in vertical alliances: joint product innovation and learning from allies. RMS 10(2):381-409

Clauß T, Bouncken RB, Laudien S, Kraus S (2019) Business model reconfiguration and innovation in SMEs: a mixed-method analysis from the electronics industry. Int J Innov Manag. https://doi. org/10.1142/S1363919620500152

Creswell JW (2013) Qualitative inquiry \& research design: choosing among five approaches, 3rd edn. SAGE, Thousand Oaks

Dubois A, Gadde LE (2002) Systematic combining: an abductive approach to case research. J Bus Res 55(7):553-560

Eisenhardt KM (1989) Building theories from case study research. Acad Manag Rev 14(4):532-550

Eisenhardt KM, Martin JA (2000) Dynamic capabilities: What are they? Strateg Manag J 21(10-11):1105-1121

Foss NJ, Saebi T (2017) Fifteen years of research on business model innovation: How far have we come, and where should we go? J Manag 43(1):200-227

Foss NJ, Saebi T (2018) Business models and business model innovation: between wicked and paradigmatic problems. Long Range Plan 51(1):9-21

Geertz C (1988) Works and lives: the anthropologist as author. Stanford University Press, Palo Alto

Greiner LE (1972) Red flags in organization development. Bus Horiz 15(3):17-24

Gummesson E (2005) Qualitative research in marketing: road-map for a wilderness of complexity and unpredictability. Eur J Mark 39(3/4):309-327

Hannan MT, Freeman J (1984) Structural inertia and organizational change. Am Soc Rev 49(2):149-164

Helfat CE, Peteraf MA (2003) The dynamic resource-based view: capability lifecycles. Strateg Manag J 24(10):997-1010

Holmqvist M (2009) Complicating the organization: a new prescription for the learning organization? Manag Learn 40(3):275-287

Kraus S, Palmer C, Kailer N, Kallinger FL, Spitzer J (2019) Digital entrepreneurship: a research agenda on new business models for the twenty-first century. Int J Entrep Behav Res 25(2):353-375

Larsson R, Bengtsson L, Henriksson K, Sparks J (1998) The interorganizational learning dilemma: collective knowledge development in strategic alliances. Organ Sci 9(3):285-305

Legner C, Eymann T, Hess T, Matt C, Böhmann T, Drews P, Ahlemann F (2017) Digitalization: opportunity and challenge for the business and information systems engineering community. Bus Inf Syst Eng 59(4):301-308

March JG (1991) Exploration and exploitation in organizational learning. Organ Sci 2(1):71-87

Mell P, Grance T (2011) National Institute of Standards and Technology, The NIST definition of cloud computing. NIST Spec Publ 53(6):50

Miles MB, Huberman AM (1994) Qualitative data analysis: an expanded sourcebook. Sage, Thousand Oaks

Miller D, Friesen PH (1984) A longitudinal study of the corporate life cycle. Manage Sci 30(10):1161-1183

Muhic M, Johansson B (2014) Cloud sourcing—next generation outsourcing? Procedia Technol 16:553-561

Ngwenyama OK, Klein HK (1994) A n exploration of expertise of knowledge workers: towards a definition of the universe of discoursefor knowledge acquisition. Inf Syst J 4:129-140

Normann R (1971) Organizational innovativeness: product variation and reorientation. Adm Sci Q $16: 203-215$

Peppard J (2001) Bridging the gap between the IS organization and the rest of the business: plotting a route. Inf Syst J 11:249-270

Ratten V (2016) Continuance use intention of cloud computing: innovativeness and creativity perspectives. J Bus Res 69(5):1737-1740

Romanelli E, Tushman ML (1994) Organizational transformation as punctuated equilibrium: an empirical test. Acad Manag J 37(5):1141-1166

Salvato C, Vassolo R (2018) The sources of dynamism in dynamic capabilities. Strateg Manag J 39(6): $1728-1752$

Schneider S, Sunyaev A (2016) Determinant factors of cloud-sourcing decisions: reflecting on the IT outsourcing literature in the era of cloud computing. J Inf Technol 31(1):1-31

Smith KG (1985) Top level management priorities in different stages of the organizational life cycle. Acad Manag J 28(4):799-820 
Spieth P, Schneckenberg D, Ricart JE (2014) Business model innovation-state of the art and future challenges for the field. R\&DManagement 44(3):237-247

Teece DJ (2007) Explicating dynamic capabilities: the nature and microfoundations of (sustainable) enterprise performance. Strateg Manag J 28(13):1319-1350

Teece DJ (2018) Business models and dynamic capabilities. Long Range Plan 51(1):40-49

Teece D, Peteraf M, Leih S (2016) Dynamic capabilities and organizational agility: risk, uncertainty, and strategy in the innovation economy. Calif Manag Rev 58(4):13-35

Tushman ML, Anderson P (1986) Technological discontinuities and organizational environments. Adm Sci Q 31(3):439-465

Vithayathil J (2018) Will cloud computing make the information technology (IT) department obsolete? Inf Syst J 28(4):634-649

Wernerfelt B (1984) A resource-based view of the firm. Strateg Manag J 5(2):171-180

Willcocks LP, Venters W, Whitley EA (2013a) Cloud sourcing and innovation: slow train coming? A composite research study. Strateg Outsourcing Int J 6(2):184-202

Willcocks L, Venters W, Whitley E (2013b) Moving to the cloud corporation: How to face the challenges and harness the potential of cloud computing. Springer, Berlin

Yin RK (1989) Case study research design and methods. Sage, Beverly Hills

Publisher's Note Springer Nature remains neutral with regard to jurisdictional claims in published maps and institutional affiliations. 